JÚLIO CÉSAR FRANCESCHET

\title{
APROVEITAMENTO ECONÔMICO DOS DIREITOS PRIVADOS DA PERSONALIDADE
}

\author{
Tese de Doutorado \\ Orientador: Professor Titular Dr. Fernando Campos Scaff
}

UNIVERSIDADE DE SÃO PAULO

FACULDADE DE DIREITO

São Paulo - SP 


\section{JÚLIO CÉSAR FRANCESCHET}

\section{APROVEITAMENTO ECONÔMICO DOS DIREITOS PRIVADOS DA PERSONALIDADE}

Tese apresentada à Banca Examinadora do Programa de Pós-Graduação em Direito, da Faculdade de Direito da Universidade de São Paulo, como exigência parcial para obtenção do título de Doutor em Direito, na área de concentração Direito Civil, sob a orientação do Prof. Titular Dr. Fernando Campos Scaff.

UNIVERSIDADE DE SÃO PAULO

FACULDADE DE DIREITO

São Paulo - SP 


\section{RESUMO}

FRANCESCHET, Júlio César. Aproveitamento econômico dos direitos privados da personalidade. 2014. 214 f. Tese (Doutorado) - Faculdade de Direito, Universidade de São Paulo, São Paulo, 2014.

A evolução histórica dos direitos privados da personalidade confunde-se, em certa medida, com os avanços e retrocessos relativos à tutela e à promoção da pessoa humana. Ofuscados pela teoria dos direitos fundamentais, os direitos privados da personalidade vivem período de verdadeira crise dogmática, afastando-se do Direito privado e aproximando-se do Direito público por força do constante apelo ao princípio da dignidade da pessoa humana. Ocorre, porém, que os direitos da personalidade devem ser estudados com os olhos voltados para o Direito privado, notadamente porque compreendem as faculdades de uso, gozo e defesa do modo de ser físico e moral da pessoa, revelando-se, assim, verdadeiros direitos subjetivos. Cuidam-se de direitos que recaem sobre bens específicos, atuais e passíveis de uso e fruição, quais sejam, os bens da personalidade. Ademais, a despeito dos pontos de intercessão, não se confundem com os direitos fundamentais e com os direitos humanos. Embora importantes instrumentos de defesa da pessoa contra ataques do Poder Público e de outros particulares (tutela negativa), os direitos da personalidade revelam dimensão positiva, caracterizada pelo seu efetivo aproveitamento, como, comumente, tem ocorrido com os direitos à imagem, à voz, à privacidade e ao nome. Os direitos da personalidade, no tecido social atual, têm se revelado compatíveis com a autonomia privada, alcançando, outrossim, expressiva valoração econômica. O aproveitamento econômico, contudo, encontra limites, não devendo se perder de vista o fundamento ético que permeia os direitos da personalidade. Os direitos da personalidade revelam, assim, dupla dimensão: uma negativa, de defesa, e outra positiva, sujeita aos influxos da autonomia privada e compatível, ademais, com o aproveitamento econômico.

Palavras-chave: Direito Privado. Direito subjetivo. Direitos da personalidade. Aproveitamento econômico. Autonomia privada. 


\section{RÉSUMÉ}

FRANCESCHET, Júlio César. Utilisation économique des droits privés de la personnalité. 2014. 214 f. Thèse (PhD) - Faculté de Droit, Université de São Paulo, São Paulo, 2014.

L'évolution historique des droits privés de la personnalité se confond, dans une certaine mesure, avec des avancées et des reculs sur la protection et la promotion de la personne humaine. Éclipsée par la théorie des droits fondamentaux, les droits privés de la personnalité vivant période dogmatique de véritable crise, loin du droit privé et de droit public se approchant de la vertu appel constant au principe de la dignité humaine. Arrive, cependant, que les droits de la personnalité doivent être étudiées avec un oeil au droit privé, notamment parce qu'ils comprennent l'utilisation des pouvoirs, la jouissance et la protection des façon d'être la personne physique et morale, révélant droits ainsi véritables subjective. Soins sont des droits qui tombent sur des valeurs spécifiques, présents et capables d'utilisation et la jouissance, à savoir, les valeurs personnelles. En outre, malgré l'intercession de points, à ne pas confondre avec les droits fondamentaux et les droits humains. Bien que les instruments de défense de personne importante contre les attaques du gouvernement et d'autres personnes (protection négative), les droits de la personnalité révèlent dimension positive, caractérisé par son utilisation réelle, comme souvent, a eu lieu avec les droits à l'image, de la voix, à la vie privée et le nom. Les droits de la personnalité, dans le tissu social d'aujourd'hui, ont prouvé pour être compatible avec l'autonomie privée, atteindre , évaluation économique ailleurs, significative. La utilisation économique, cependant, trouve des limites et ne doit pas être perdu de vue le fondement éthique qui imprègne les droits de la personnalité. Les droits personnels révèlent donc deux dimensions: un négatif, de la défense, et d'autres positifs, soumis à des entrées de l'autonomie privée et compatible avec l'utilisation économique.

Mots-clés: Droit privé. Droit subjectif. Les droits de la personnalité. La reprise économique. Autonomie privée. 


\begin{abstract}
FRANCESCHET, Júlio César. Economic use of private rights of personality. 2014. 214 f. Thesis (Ph.D.) - Faculty of Law, University of São Paulo, São Paulo, 2014.

The historical development of the private rights of personality is confused with advances and setbacks on the protection and promotion of the human person. Overshadowed by the theory of fundamental rights, private rights of personality living dogmatic period of real crisis, away from the private law and approaching the public law under constant appeal to the principle of human dignity. Happens, however, that personality rights should be studied with an eye to the private law, notably because they understand the use of attributes, enjoyment and protection of way of being physical and moral person, revealing thus true rights subjective. Care are rights that fall on specific goods, present and capable of use and enjoyment, namely, the personal values. Moreover, despite the intercession of points, not to be confused with the fundamental rights and human rights. Although important person defense instruments against the Government attacks and other individuals (negative protection), the rights of personality reveal positive dimension, characterized by its actual use, as commonly, has occurred with the rights to the image, voice, to privacy and name. Personality rights, currently, have proven to be compatible with the private autonomy, reaching, moreover, significant economic valuation. The economic use, however, finds limits and should not be lost sight of the ethical foundation that permeates the rights of personality. The personal rights reveal thus two dimensions: a negative, defense, and other positive, subject to inflows of private and compatible autonomy, moreover, with the economic use.
\end{abstract}

Keywords: Private Law. Subjective right. Personality rights. Economic recovery. Private autonomy . 


\section{INTRODUÇÃO}

Historicamente, como bem destacado por Caio Mário da Silva Pereira $^{1}$, a proteção conferida aos direitos da personalidade mostrou-se presente em todos os tempos e em todas as fases da civilização romano-cristã, embora carecesse de sistematização, especialmente no contexto das relações privadas.

A proteção da pessoa sempre ocupou lugar de destaque nas civilizações pretéritas, seja através de ações judiciais visando coibir ofensas corporais e morais, seja, ainda, através da legitimação da vingança privada.

António Menezes Cordeiro, em estudo sobre a evolução doutrinária e jurisprudencial dos direitos da personalidade no ordenamento jurídico português, aponta que, no campo publicístico, a tutela dispensada aos cidadãos mostrou-se presente desde as Ordenações do Reino, revelando-se verdadeiro princípio geral de direito. $^{2}$

Contudo, destaca António Menezes que a inserção dos direitos da pessoa no campo das relações privadas somente foi levada a efeito com o Código Civil Português de 1867, no capítulo intitulado "direitos originários". Embora tenham sido numerosas as críticas aos denominados "direitos originários", os direitos da personalidade, graças a influências do Direito Germânico e Italiano, firmaram-se como categoria autônoma, ocupando lugar de destaque no cenário

\footnotetext{
${ }^{1}$ Sobre a proteção conferida aos direitos da personalidade ao longo dos tempos, acrescenta Caio Mário da Silva Pereira que: "Conceitos, normativos como teóricos, asseguraram sempre condições mínimas de respeito ao indivíduo, como ser, como pessoa, como integrante da sociedade. Todos os sistemas jurídicos, em maior ou menor escala, punem os atentados contra a vida, à integridade tanto física quanto moral". (PEREIRA, Caio Mário da Silva. Instituições de direito civil: introdução ao direito civil. $21^{\text {a }}$ ed. Rio de Janeiro: Forense, 2005. v. 1. p. 238).

${ }^{2}$ CORDEIRO, António Menezes. Os direitos da personalidade na civilística portuguesa. In Estudos em Honra do Professor Doutor Inocêncio Galvão Telles, organizados no âmbito do Conselho Científico da Faculdade de Direito de Lisboa. Disponível em <http://www.estig.ipbeja.pt/ ac_direito/MCordeiro2001.pdf $\geq$. Acesso: 10 fev. 2012. p. 1230.
} 
jurídico português, especialmente após 1983, quando passaram a ser implantados, ganhando corrente aplicação a partir de $1993 .^{3}$

Ainda sobre a sistematização dos direitos da personalidade no campo das relações privadas, Daisy Gogliano lembra a importância do Direito Germânico, cujo expoente, neste estudo, foi Samuel Strick (morto em 1710, que ensinou em Leipzig). Destaca, ademais, o trabalho de Donellus (Hugo Doneau) responsável pela obra 'Comentariorum Juris Civilis Libri', trazendo a lume a concepção de direito subjetivo, a facultas agendi, o poder de agir de acordo com a norma jurídica (e não de acordo com a razão pura). ${ }^{4}$

A despeito dos estudos desenvolvidos à luz do Direito privado, os direitos da pessoa destacaram-se inicialmente no contexto das relações públicas e tiveram como objetivo primeiro a limitação da atuação Estatal na esfera privada; surgem, portanto, como instrumentos de defesa contra a prepotência e os abusos das autoridades ${ }^{5}$.

Já como categoria autônoma, os direitos da personalidade, na lição de Rubens Limongi França, podem ser definidos como as "faculdades jurídicas cujo objeto são os diversos aspectos da própria pessoa do sujeito, bem assim as suas emanações e prolongamentos" ${ }^{6}$. Em sentido semelhante, ensina Nestor Duarte que o "objeto dos direitos da personalidade são as faculdades jurídicas que se situam no âmbito da própria pessoa"7.

Os direitos da personalidade estão, portanto, diretamente associados ao uso e ao gozo daqueles bens essenciais e inerentes à pessoa.

\footnotetext{
${ }^{3}$ Destaca o autor português que "o Código de Seabra ficara com o que, no século XIX, maior relevo deu aos hoje ditos 'direitos da personalidade"' (CORDEIRO, António Menezes. Os direitos da personalidade na civilística portuguesa. In Estudos em Honra do Professor Doutor Inocêncio Galvão Telles, organizados no âmbito do Conselho Científico da Faculdade de Direito de Lisboa. Disponível em <http://www.estig.ipbeja.pt/ ac_direito/MCordeiro2001.pdf. . Acesso: 10 fev. 2012. p.1235).

${ }^{4}$ GOGLIANO, Daisy. Revista de Direito Sanitário, vol. 1, n. 1, Nov/2000, p. 113.

${ }^{5}$ PEREIRA, Caio Mário da Silva. Instituições de direito civil: introdução ao direito civil. $21^{\text {a }}$ ed. Rio de Janeiro: Forense, 2005. v. 1. p. 239.

${ }^{6}$ FRANÇA, Rubens Limongi. Enciclopédia saraiva do direito. São Paulo: Saraiva, 1978. v. 28.

${ }^{7}$ DUARTE, Nestor. Código civil comentado. 5aㅡ ed. São Paulo: Manole, 2011. p. 28.
} 
Tratam-se de direitos que recaem sobre bens atuais e específicos, que dizem respeito ao modo de ser físico e psíquico da pessoa.

A aparente confusão entre sujeito e objeto torna controvertida a natureza jurídica dos direitos da personalidade. É possível identificar ao menos duas correntes de pensamento bem delimitadas sobre o tema: a primeira delas defende que os direitos da personalidade são direitos subjetivos, devendo ser disciplinados à luz do Direito privado; a segunda, por sua vez, critica a concepção privada dos direitos da personalidade, acrescentando, ademais, mostrar-se a estrutura dogmática do direito subjetivo insuficiente à proteção e promoção da pessoa. Nesta ordem de ideias, os direitos da personalidade representariam verdadeira cláusula geral de tutela e promoção da pessoa em consonância com o princípio constitucional da dignidade humana.

No Brasil, o discurso jurídico-filosófico atual, impregnado pela teoria dos direitos e garantias fundamentais, tem aproximado os direitos da personalidade do princípio constitucional da dignidade da pessoa humana, afastando-os, por consequência, da tutela e disciplina do Direito privado.

É oportuno destacar, ademais, que, ao longo dos anos, os direitos da personalidade foram estudados, sobretudo, sob o aspecto negativo, ou seja, a partir dos instrumentos postos à disposição do seu titular visando coibir lesão ou ameaça de lesão.

Neste contexto, desenvolveram-se institutos visando à reparação dos direitos da personalidade violados, a exemplo do dano moral, e também providências inibitórias, de caráter preventivo. A propósito, ressaltando o aspecto negativo, ensina Orlando Gomes ${ }^{8}$ que os direitos da personalidade "(...) destinam-

\footnotetext{
${ }^{8}$ GOMES, Orlando. Introdução ao direito civil. 20 ed. Rio de Janeiro: Forense, 2010. p. 130. Ainda neste sentido, "os direitos da personalidade são estudados sob a ótica do direito privado, considerados como a garantia mínima da pessoa humana para as suas atividades internas e para as suas projeções ou exteriorizações para a sociedade. Para isso, impõem à coletividade uma conduta negativa, evitando embaraço ao seu exercício. Já as liberdades públicas são condutas individuais ou coletivas realizadas de forma autodeterminada, em face de autorização expressa ou implícita, conferida pelo Estado [...] - grifamos no original (CARVALHO NETO, Inácio de. Curso de Direito Civil: parte geral. São Paulo: Atlas, 2006, p. 126).
} 
se a resguardar a eminente dignidade da pessoa humana, preservando-a dos atentados que pode sofrer por parte dos outros indivíduos” (grifo nosso).

Entretanto, a evolução dos meios de comunicação, da tecnologia, da cibernética e, sobretudo, a maior compreensão da pessoa sobre seu próprio corpo e os atributos de sua personalidade têm conduzido, nos dias atuais, à efetiva fruição dos direitos da personalidade, alçando-os à categoria de liberdades positivas. Antes tutelados predominantemente sob o aspecto negativo, os direitos da personalidade passam a ser exercidos de forma positiva, tornando-se, com frequência, objeto de negócios jurídicos.

No cenário jurídico-social atual, os direitos da personalidade revelam dupla dimensão: uma negativa ou defensiva, voltada à reparação dos danos decorrentes da injusta violação ou a cessação da ameaça de lesão, naqueles casos em que o dano efetivo ainda não foi causado; e outra positiva, caracterizada pelo aproveitamento, sobretudo econômico, dos bens que integram a personalidade.

Ao longo deste trabalho, a expressão "tutela positiva" será empregada para designar 0 aproveitamento dos direitos privados da personalidade, sobretudo no contexto das relações negociais, contrapondo-se à tutela negativa, que se apresenta como a faculdade de fazer cessar lesão ou ameaça de lesão, além de reclamar a reparação dos danos decorrentes de injusta violação.

A tutela positiva aqui tratada tem revelado, na atualidade, um número expressivo de negócios jurídicos que têm por objeto direitos da personalidade. A título de exemplo, podem ser citados os contratos de cessão de imagem e de voz, exploração de privacidade em realities shows, cessão de direitos autorais, entre outros.

A contratualização dos direitos da personalidade está presente no tecido social atual, rompendo-se, assim, com a dimensão unicamente negativa inicialmente dedicada a esses direitos. 
Não bastasse a qualificação extrapatrimonial conferida inicialmente aos direitos da personalidade, parece não mais coadunar-se com o seu aproveitamento. Isso porque o atual estado da matéria confere aos bens da personalidade, a exemplo do que ocorre com os direitos à imagem, à voz, à intimidade, entre vários outros, manifesto conteúdo econômico, permitindo, assim, ao seu titular a obtenção de vantagens patrimoniais decorrentes da sua inserção em relações negociais.

A doutrina nacional, ${ }^{9}$ a despeito do disposto no artigo 11 do Código Civil Brasileiro ${ }^{10}$, já reconhece que alguns direitos da personalidade são disponíveis, desde que a disposição seja temporária e relativa. A este propósito, registra Maria Helena Diniz que os direitos da personalidade "poderão ser objeto de contrato como, por exemplo, o de concessão ou licença para uso de imagem ou de marca (se pessoa jurídica). (...) Como se vê, a disponibilidade dos direitos da personalidade é relativa" ${ }^{11}$.

António Menezes Cordeiro, embora com os olhos voltados ao Código Civil Português, vai além, defendendo que os direitos privados da personalidade "representam, como quaisquer outros direitos subjetivos, posições de liberdade, reconhecidas ao seu beneficiário. Nessa qualidade, eles implicam disponibilidade"12.

Assim, a despeito da previsão normativa contida no Código Civil Brasileiro, os direitos da personalidade são compatíveis com limitações

\footnotetext{
${ }^{9}$ BITTAR, Carlos Alberto. Os direitos da personalidade. $7^{\underline{a}}$ ed. Rio de Janeiro: Forense Universitária, 2004. p. 12.

${ }^{10}$ Art. 11. Com exceção dos casos previstos em lei, os direitos da personalidade são intransmissíveis e irrenunciáveis, não podendo o seu exercício sofrer limitação voluntária.

${ }^{11}$ DINIZ, Maria Helena. Curso de direito civil brasileiro: teoria geral do direito civil. 24a ed. São Paulo: Saraiva, 2007. v.1. p. 119.

${ }^{12}$ CORDEIRO, António Menezes. Tratado de direito civil português: parte geral. Coimbra: Almedina, 2004. v.3.. p. 105 e 106. As grandes restrições advêm da não-patrimonialidade de vários deles e da inerência de todos: o Direito poderá consentir em limitações graciosas e temporárias: mas não na sua troca por dinheiro ou numa alienação definitiva. Quanto à graciosidade, será o caso dos direitos do círculo biológico e do círculo moral. Todavia, apenas caso a caso será possível formular um juízo definitivo. No tocante à temporalidade: 0 artigo 81.ำ fixa numa regra de livre revogabilidade, "... ainda que com obrigação de indemnizar os prejuízos causados às legítimas expectativas da outra parte" (Ibid., p. 115).
} 
decorrentes da vontade, voltadas ao seu efetivo aproveitamento, especialmente no contexto das relações negociais.

Conforme acima revelado, aspecto fundamental da tutela positiva dos direitos da personalidade diz respeito ao seu aproveitamento econômico. Isso porque alguns bens da personalidade, em decorrência do seu aproveitamento, passaram a ter valoração econômica. É o que ocorre, por exemplo, com a cessão do direito à imagem e com a exploração econômica da privacidade em alguns programas de televisão. Mais recentemente, a discussão em torno das biografias não autorizadas revelou muito mais do que elementos morais da personalidade; estão em causa também fatores econômicos, relativos ao aproveitamento dos bens que integram a personalidade do biografado.

Os direitos da personalidade, uma vez inseridos no comércio jurídico, passaram a revelar, além do conteúdo moral já presente desde a sistematização da categoria, sua dimensão patrimonial.

Segundo António Menezes Cordeiro, ${ }^{13}$ existem os direitos de personalidade: (i) não patrimoniais em sentido forte, que corresponderia aos direitos que não admitem uma tradução pecuniária e cita como exemplo o direito à vida, à saúde e à integridade corporal, (ii) não-patrimoniais em sentido fraco, como aqueles que podem ter um alcance patrimonial, embora respeitando certas regras, citando como exemplo o direito à saúde e à integridade física, quando utilizados para fins científicos, desde que não irreversivelmente atingidos, e (iii) patrimoniais, que seriam aqueles negociáveis no mercado, mas que permanecem sendo tutelados pelas regras específicas dos direitos de personalidade por se referirem aos bens de personalidade, tendo mencionado como exemplo os direitos ao nome, imagem e os decorrentes de atividade intelectual.

Todas estas questões mostram-se relevantes porque 0 aproveitamento econômico dos direitos da personalidade é uma realidade jurídica e social, e, à míngua de critérios científicos, o princípio constitucional da

${ }^{13}$ CORDEIRO, António Menezes. Tratado de direito civil português: parte geral. Coimbra: Almedina, 2004. v.3. p.111. 
dignidade da pessoa humana acaba sendo usado com pouco rigor técnico, fornecendo soluções casuísticas apoiadas, na maioria das vezes, em conceitos jurídicos indeterminados.

A despeito de todas essas questões, que revelam a vivacidade da matéria, ao nosso sentir, os direitos da personalidade vivem um momento de crise conceitual. A aproximação dos direitos da personalidade ao princípio da dignidade da pessoa humana pouco contribui para a sistematização e compreensão das novas demandas em torno desse tema. Apesar da relevância constitucional, o princípio da dignidade humana, no contexto das relações privadas, têm revelado respostas pouco satisfatórias, justificando comportamentos absolutamente díspares.

No caso dos direitos da personalidade, pensamos que é preciso reavivar as fronteiras entre o Direito público e o Direito privado, extremando-os, conceitualmente, dos direitos fundamentais e dos direitos humanos. Apesar dos pontos de intercessão, os direitos da personalidade radicam sua origem no Direito privado, devendo, assim, ser sistematizados e compreendidos à luz das relações privadas, sobretudo do conceito de direito subjetivo.

Defendemos que o constante apelo ao princípio da dignidade da pessoa humana, no específico estudo dos direitos da personalidade, acaba por subtrair da pessoa aquilo que ela tem de mais valioso que é a sua autonomia. Além disso, acaba por reduzir os direitos da personalidade a meros instrumentos de defesa, impedindo o seu desenvolvimento como liberdades positivas.

A experiência tem mostrado que, no estudo dos direitos da personalidade, o princípio da dignidade da pessoa humana, dada a banalização do seu emprego, tem-se revelado como uma fórmula vazia, que tudo e nada justifica.

Atentos à crise conceitual enfrentada pelos direitos da personalidade e certos de que revelam uma dimensão negativa e outra positiva, compatível, inclusive, com o aproveitamento econômico, na primeira parte desse trabalho, 
procuramos identificá-los como categorias de Direito privado, reavivando fronteiras que, apesar das críticas, são indispensáveis à melhor sistematização e compreensão da matéria. Defendemos que os direitos da personalidade revelamse verdadeiros direitos subjetivos privados, que recaem sobre bens atuais, específicos e passíveis de apreensão.

Na segunda parte, dedicamo-nos à dimensão positiva dos direitos da personalidade. Conforme já apontado acima, os direitos da personalidade não podem ser identificados apenas como posições de defesa. Apesar da importância histórica e dogmática, os avanços tecnológicos e a evolução dos costumes têm revelado que os bens da personalidade são passíveis de efetivo aproveitamento.

Neste novo contexto, revela-se indispensável compreender o papel da autonomia privada no aproveitamento dos direitos da personalidade. Isso porque, dado o fundamento ético que permeia os direitos da personalidade, é preciso estabelecer limites quanto ao seu aproveitamento, sendo certo que os negócios jurídicos que têm por objeto bens da personalidade sujeitam-se a regime especial quanto à execução das obrigações ajustadas e, ainda, quanto à extinção do vínculo obrigacional.

Por fim, ocupamo-nos do aproveitamento econômico dos direitos da personalidade. Os direitos da personalidade, historicamente, sempre foram apontados como instrumentos voltados à defesa dos elementos morais da pessoa. Tratam-se, portanto, de direitos extrapatrimoniais, despidos de valoração econômica direta.

Ocorre, porém, que o aproveitamento dos direitos da personalidade tem revelado a sua dimensão patrimonial. Alguns direitos da personalidade são frequentemente inseridos em relações contratuais, alcançando valoração pecuniária expressiva. $\mathrm{O}$ aproveitamento dos direitos privados da personalidade fomenta a sua dimensão patrimonial, tornando, assim, duvidoso o tratamento extrapatrimonial a eles dedicado. 
Outrossim, o critério comumente empregado para distinguir as relações patrimoniais e extrapatrimoniais revela-se, ao nosso sentir, insatisfatório, de modo que a dimensão patrimonial dos direitos privados da personalidade não se mostra incompatível com a sua natureza jurídica.

Neste cenário, com rigor científico e atentos aos estudos, nacionais e estrangeiros a que tivemos acesso durante a pesquisa, buscamos analisar, de forma crítica, o estágio atual dos direitos privados da personalidade a fim de melhor compreender o seu aproveitamento e a sua valoração pecuniária, tão presentes na atualidade. Para tanto, conforme acima exposto, julgamos necessário reavivar as fronteiras entre o Direito público e o Direito privado, extremando conceitualmente os direitos da personalidade de outras categorias que têm em comum a tutela e a proteção da pessoa.

Buscamos, assim, contribuir para o avanço da ciência jurídica nacional, revisitando a definição e as características dos direitos privados, com vistas a melhor compreender e sistematizar o seu aproveitamento econômico.

Não temos a pretensão de esgotar a matéria, caracterizada, ademais, por um dinamismo particular; tampouco buscamos por respostas definitivas. Isso porque, na Ciência do Direito, como adverte Larenz, ${ }^{14}$ "é-nos, em todo caso, lícito acreditar que nos chega à mão, aqui e ali, um pedaço do fio cujo fim é para nós oculto".

${ }^{14}$ LARENZ, Karl. Metodologia da ciência do direito. Lisboa: Fundação Calouste Gulbenkian, 1983. p. 203. 


\section{CONCLUSÃO}

Embora recaiam sobre o modo de ser físico e moral da pessoa, promovendo, em sentido ampliado, a sua tutela, os direitos privados da personalidade não se confundem com os direitos fundamentais e com os direitos humanos.

Os direitos fundamentais radicam sua origem no Direito público e recaem sobre os mais diversificados bens e interesses, não se limitando aos elementos da personalidade. Já os direitos humanos consagraram-se no Direito Internacional a partir de um conceito universal de dignidade humana; falta-Ihes a especificidade e a atualidade que caracteriza os bens da personalidade.

Em certa medida, a aproximação dos direitos privados da personalidade aos direitos fundamentais foi relevante para firmar a proteção da pessoa humana e sua tutela, inclusive no contexto das relações privadas.

Contudo, os direitos da personalidade encontram disciplina e sistematização no Direito privado, que, a despeito das críticas, remanesce distinto, por motivos vários, do Direito público. É no Direito privado que os direitos da personalidade radicam a sua origem e florescem como verdadeiros direitos subjetivos.

A identificação dos direitos privados da personalidade, como tem comumente ocorrido no Brasil, com o princípio da dignidade da pessoa humana não se revela inteiramente adequada. Reconhecemos que o apelo a princípios constitucionais é importante, notadamente no que diz respeito à ampla promoção e à tutela da pessoa humana. Contudo, o apelo indiscriminado a conceitos amplos pode tudo e nada justificar ao sabor dos interesses do intérprete.

Não somos contrários ao princípio da dignidade da pessoa humana. Somos contrários à banalização do emprego desse princípio constitucional, que, 
sem rigor técnico, tem se revelado vazio e de difícil aplicação prática, sobretudo no contexto das relações privadas.

Pode-se dizer que a dicotomia Direito público/privado encontra-se superada. Dicotomia, de fato, não existe, dada a necessidade de coesão e harmonia do sistema jurídico. Entretanto, Direito público e Direito privado continuam, a despeito das críticas, revelando mais diferenças do que semelhanças.

Ideologicamente o Direito privado não se confunde com o Direito público, representando aquele espaço dedicado às lides diárias, ao convívio de igual para igual, aquele espaço dotado de liberdade e de autonomia, no qual a intervenção direta e imediata do Estado é, em regra, desnecessária. Por mais que o Estado, ao longo da história, venha mais e mais interferindo e direcionando as relações privadas, é inegável que o espaço privado continua marcado por espeficidades que o tornam manifestamente distinto do público.

Arriscamos dizer que nas relações privadas, cotidianas, simples e necessárias, o princípio da segurança jurídica, decorrente da aplicação de regras claras, elaboradas, em regimes democráticos como o nosso, pelos representantes do povo, é dotado de maior importância do que qualquer outro conceito vago e difícil compreensão.

É neste sentido que concluímos ser importante resgatar as diferenças entre o Direito público e o Direito privado. Não significa dizer que o Direito privado seja o mesmo de três séculos atrás. A sociedade é outra e o Estado abstencionista deixou de existir. Contudo, é preciso compreender que o espaço privado permanece vivo e com ele ganha destaque o Direito privado e o seu conjunto de regras próprias.

Neste cenário, concluímos que só podemos compreender o estágio atual dos direitos da personalidade com os olhos voltados para o Direito privado. Tratam-se, em conclusão, de direitos subjetivos privados que têm por objeto específicos e atuais bens, os da personalidade. Revelam, assim, as faculdades 
que recaem sobre o modo de ser físico e moral da pessoa. É a partir desse conceito que rejeitamos a ideia de um direito geral da personalidade, fundado na ampla tutela e na promoção da pessoa.

Os direitos da personalidade revestem-se de natureza privada e permitem o uso e a fruição dos bens sobre os quais recaem. Esses bens são a imagem, o nome, a voz, a intimidade, a privacidade, a produção intelectual, a honra e a integridade física. A vida, por sua vez, não pode ser qualificada como direito, já que é pressuposto para o exercício de qualquer direito. A vida é tutelada de diversas formas e em variados diplomas legislativos, revelando-se abolutamente inadequada a sua quaiflicação como direito subjetivo.

É certo que os direitos da personalidade foram inicialmente concebidos para defender a pessoa dos ataques do Poder Público e, mais tarde, de outros particulares. Tratavam-se, assim, de categorias de defesa, voltados à proteção dos bens da personalidade. Ocorre, porém, que os direitos da personalidade têm revelado outra dimensão, além daquela negativa, de defesa. Com efeito, os direitos privados da personalidade têm-se mostrado compatíveis com o aproveitamento consentido, ou, em outras palavras, com o uso e gozo dos bens que integram a personalidade.

Neste cenário, tornaram-se comuns e juridicamente aceitáveis negócios jurídicos que têm por objeto direitos da personalidade, a exemplo do que ocorre com os direitos à imagem, à voz, ao nome e, mais recentemente, à privacidade. Assim, a despeito do contido no artigo 11 do Código Civil Brasileiro de 2002, os direitos da personalidade são passíveis de sofrer limitações voluntárias, decorrentes do princípio do autonomia privada.

O aproveitamento dos direitos privados da personalidade é um dado social recente, revelador da importância da autonomia privada no uso e fruição desses direitos. Os direitos da personalidade, como direitos subjetivos, são, portanto, compatíveis com o aproveitamento, não se limitando, assim, à defesa nos casos de lesão ou de ameaça de lesão. 
As tutelas negativa, de defesa, e positiva, de aproveitamento, coexistem no estágio atual dos direitos privados da personalidade. É preciso, contudo, não se perder de vista o fundamento ético que permeia os direitos da personalidade a fim de que os limites da autonomia privada nesse tema possam ser identificados.

Como estão em causa direitos que recaem sobre o modo de ser físico e moral da pessoa, devem ser vedados negócios jurídicos que exponham a pessoa a situações degradantes, aviltantes, devendo ser afastada a validade do consentimento prestado nestes casos.

Não é tarefa fácil identificar os casos em que o consentimento será inválido, cabendo ao intérprete, com os olhos voltados para a atualidade, perquirir a preservação do fundamento ético dos direitos da personalidade.

Ademais, os negócios jurídicos que têm por objeto direitos da personalidade sujeitam-se a um regime especial, permitindo, por exemplo, a revogação unilateral do consentimento quando em causa os elementos morais da personalidade. Outrossim, referidos negócios jurídicos, quando exigirem a atuação imediata do titular do direito da personalidade, revelam-se, em caso de iandimplemento, incompatíveis com a execução específica, sob pena de grave comprometimento da liberdade individual.

Concluimos que a revogação unilateral do consentimento nos negócios jurídicos que têm por objeto direitos da personalidade somente se revela de fato liberatória quando fundada no elemento moral ou ético da personalidade. A revogação unilateral não se coaduna com motivos unicamente patrimoniais, devendo, nestes casos, ser a obrigação convertida em perdas e danos, caso revele-se impossível a execução específica.

Ainda, em homenagem à segurança das relações jurídicas, deve-se, quando invocados motivos unicamente patrimoniais, incompatíveis, portanto, com a revogação unilateral do consentimento prestado, prestigiar a execução 
específica quando os negócios jurídicos não dependerem da intervenção direta e imediata dos titular dos direitos da personalidade.

Concluímos, ademais, que o aproveitamento dos direitos da personalidade, fruto da autonomia privada, revela outro elemento importante, qual seja, o seu conteúdo econômico.

Com efeito, alguns direitos da personalidade, especialmente quando inseridos em relações negociais, revelam forte conteúdo econômico. Os direitos à imagem, ao nome e à privacidade, por exemplo, têm manifesto conteúdo patrimonial notadamente na sociedade de consumo atual em que são comumente associados a produtos e a serviços.

Assim, concluímos que, a despeito das características que inicialmente lhe foram atribuídas, os direitos da personalidade, quando inseridos no comércio jurídico, revelam conteúdo patrimonial. O resultado econômico não é um dado estático. Nenhum bem ou direito pode, em abstrato, ser qualificado como patrimonial ou extrapatrimonial. É o comércio jurídico ou a inserção de um bem ou direito no específico contexto de uma relação jurídica que revela o seu conteúdo econômico.

Os bens da personalidade, inicialmente concebidos como categorias de defesa, ficaram afastados do comércio jurídico, restando, assim, destinados à tutela dos elementos morais da pessoa. Uma vez afastados do comércio jurídico, os direitos da personalidade não revelaram qualquer conteúdo econômico.

Contudo, os direitos da personalidade deixaram as posições exclusivas de defesa, tornando-se compativeis com as limitações decorrentes da vontade e com o consequente aproveitamento - uso e fruição. Neste novo cenário, os direitos da personalidade, com as limitações que the são inerentes, decorrentes da ordem pública, dos bons costumes, da boa-fé e atentos, ainda, ao seu fundamento ético, passaram a ser inseridos em relações negociais, revelando conteúdo econômico. 
O aproveitamento econômico não é incompatível com os direitos da personalidade. É preciso, contudo, cautela na verificação dos limites da autonomia privada a fim de que o fundamento ético dos direitos da peronalidade seja preservado.

Além disso, não consideramos correta a dissociação entre os elementos morais e patrimoniais da personalidade, a exemplo do que ocorre no direito estadunidense com os right of privacy e right of publicity. Os elementos morais e patrimoniais são indissociáveis, frutos de um mesmo bem, sobre o qual recai o direito da personalidade.

Embora caracterizados por um dinamismo particular, é possível, neste estágio de evolução da matéria, concluir que o aproveitamento econômico é compatível com a natureza privada dos direitos da personalidade, sendo fruto, outrossim, da atual inserção desses bens no contexto das relações privadas.

Registramos, por fim, que não temos a pretensão de oferecer respostas definitivas sobre $\mathrm{o}$ aproveitamento dos direitos da personalidade. Procuramos desenvolver um trabalho sobre o atual estágio de desenvolvimento da matéria, certos de que o dinamismo que caracteriza os direitos da personalidade invariavelmente exigirá novas respostas para novas perguntas. 


\section{REFERÊNCIAS}

ALPA, Guido; BESSONE, Mario. II diritto private oggi. In: ALPA, G., BESSONE, M. Elementi di diritto privato. Itália: Laterza, 2001. Cap. I. p. 3-84.

ALVES, Alexandre Ferreira Assumpção. A pessoa jurídica e os direitos da personalidade. Rio de Janeiro: Renovar, 1998.

ALVES, Alexandre Ferreira Assumpção. O elemento subjetivo da relação jurídica. Revista Trimestral de Direito Civil - RTDC. Rio de Janeiro, n. 5, p. 23- 49, jan./mar. 2001.

AMARAL, Francisco. Direito civil: introdução. $7^{\text {a }}$ ed. Rio de Janeiro: Renovar, 2008.

ASCENSÃO, José de Oliveira, Direito Civil: teoria geral. Coimbra: Coimbra Editora, 2002. v.1.

. Direito civil: teoria geral, relações e situações jurídicas. Coimbra: Coimbra Editora, 2002. v.3.

- Pessoa, direitos fundamentais e direitos de personalidade. Revista Trimestral de Direito Civil - RTDC. Rio de Janeiro, n. 26, p. 43-66, abr/jun. 2006.

. Pessoa, direitos fundamentais e direito da personalidade. In: ALVES, Jones Figueredo, DELGADO, Mário Luiz. (Org.). Questões controvertidas no código civil. São Paulo: Método, 2007. Cap. 4. p. 105-128.

. Direito de autor e direitos conexos. Coimbra: Coimbra Editora, 2012.

AZEVEDO, Antônio Junqueira. Caracterização jurídica da dignidade da pessoa humana. Revista USP, n. 53, p. 90-101, 2002.

Novos estudos e pareceres de direito privado. São Paulo: Saraiva, 2009. 
BARCELLONA, Pietro. Diritto privato e societá moderna. Itália: Jovene, 1996.

BELTRÃO, Sílvio Romero. Direitos da personalidade de acordo com o novo código civil. São Paulo: Atlas, 2005.

BÉNABENT, A. Les contrats spéciaux civils et commerciaux. Montchrestien, Précis Domat, 7e éd. n 995, 2006.

BERNET, Carlos J. Maluquer de Motes. Los llamados derechos de la personalidad. In: BERNET, Carlos J. Maluquer de Motes (Coord.) Codificación, persona y negocio jurídico. Barcelona: Bosch, 2003. Cap.6. p.85-103.

BICHON-LEFEUVRE, Marie-Emmanuelle. Les conventions relatives aux droits de la personnalité. Tese de Doutorado. Paris: Université de Paris XI, 1998.

BITTAR, Carlos Alberto. Os direitos da personalidade. $7^{\mathrm{a}}$ ed. Rio de Janeiro: Forense Universitária, 2004.

. Teoria geral do direito civil. $2^{\underline{a}}$ ed. São Paulo: Forense Universitária, 2009.

BORGES, Roxana Cardoso Brasileiro. Disponibilidade dos direitos da personalidade e autonomia privada. São Paulo: Saraiva, 2005.

BRASILEIRO, Ricardo. Os direitos da personalidade. Revista Jurídica do Centro Acadêmico Afonso Pena, Belo Horizonte, ano 2, n. 2, p. 43-62, 1996/1997.

BRUGUIERE, J. M. Le droit à l'image est un possible objet de contrat (et une source nouvelle de propriété incorporelle?, note ss CA Versailles, 22 sept. 2005: Légipresse 2006, n. 231, III, no 9.

CAHALI, Yussef Said. Dano moral. $2^{\mathrm{a}}$ ed. São Paulo: Revista dos Tribunais, 1999. 
CAMPOS, Diogo Leite de. Lições de Direitos da Personalidade. In: Separata do Boletim da Faculdade de Direito da Universidade de Coimbra, Vol. LXVI, $2^{\underline{a}}$ edição, 1992.

O direito e os direitos da personalidade. In: Nós - Estudos sobre o Direito das Pessoas. Coimbra: Almedina, 2004.

CARVAlHO NETO, Inácio de. Curso de Direito Civil: parte geral. São Paulo: Atlas, 2006.

CATALA, P. La transformation du patrimoine dans le droit civil moderne: RTD civ. , n.ำ25, p. 85, 1966.

CHAMBRUN, Caroline. Les contrats portanto sur les droits de la personnalité. Dissertação de Mestrado. Paris: Paris I, 1996.

CHAVES, Antônio. Direito à vida e ao próprio corpo. São Paulo: Revista dos Tribunais, 1997.

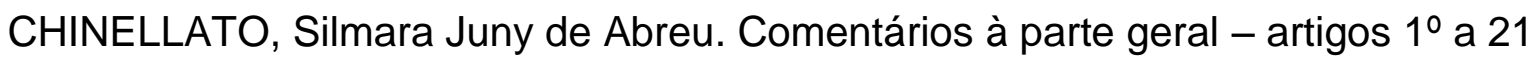
do Código Civil. In: MACHADO, Antônio Cláudio da Costa. Código civil Interpretado: artigo por artigo, parágrafo por parágrafo. 5a ed. Barueri: Manole, 2012.

CIFUENTES, Santos. Derechos personalísimos. 2a․ ed. Buenos Aires: Astrea:, 1995.

COELHO, Fábio Ulhôa. Direito a imagem. In: ALVES, Jones Figueredo,; DELGADO, Mário Luiz. (Org.). Questões controvertidas no código civil. São Paulo: Método, 2007. Cap. 7. p. 170-177.

CORDEIRO, António Menezes. Os direitos da personalidade na civilística portuguesa. In: Estudos em Honra do Professor Doutor Inocêncio Galvão Telles, organizados no âmbito do Conselho Científico da Faculdade de $\begin{array}{llll}\text { Direito de Lisboa. } & \text { Disponível em }\end{array}$ 
<http://www.estig.ipbeja.pt/ ac_direito/MCordeiro2001.pdfhttp://www.estig.ipbeja.p t/ ac_direito/MCordeiro2001.pdf $\geq$. Acesso: 10 fev. 2012.

CORDEIRO, António Menezes. Tratado de direito civil português: parte geral. $2^{\underline{a}}$ ed. Coimbra: Almedina, 2002. v. 2.

- Tratado de direito civil português: parte geral. $3^{\text {a }}$ ed. Coimbra: Almedina, 2004. v. 3.

COSTA JÚNIOR, Paulo José. O direito de estar só: tutela penal da intimidade. São Paulo: Revista dos Tribunais, 1998.

CUNHA, Paulo de Pitta e. Teoria Geral do Direito Civil. Resumo das lições proferidas no ano lectivo de 1971-1972, edição dos Serviços Sociais da Universidade de Lisboa.

DE CUPIS, Adriano. I diritti della personalità. Milano: Giuffrè, 1982.

DE MATTIA, Fábio Maria. Direitos da personalidade: aspectos gerais. In: CHAVES, A. Estudos de direito civil. São Paulo: Revista dos Tribunais, 1979.

DESBOIS, Henri. Le droit d'auteur. 3ª ed. Paris: Dalloz, 1978.

DIEZ-PICAZO, Luiz; GULLON, Antonio. Los derechos de la personalidad. In: DIEZ-PICAZO, Luiz; GULLON, Antonio. Instituciones se derecho civil: introduccion parte general, derecho de la persona. Madrid: Tecnos, 1995. Cap. 17. p.211-251. v.1.

DINIZ, Maria Helena. Curso de direito civil brasileiro: teoria geral do direito civil. 24ํㅡㄹ. ed. São Paulo: Saraiva, 2007. v.1.

DONEDA, Danilo. Os direitos da personalidade no código civil. Revista da Faculdade de Direito de Campos, Ano VI, n.ํ 6, 2005.

DUARTE, N. Código civil comentado. 5ª ed. São Paulo: Manole, 2011. 
FACHIN, Luiz Edson. Estatuto Jurídico do Patrimônio Mínimo. Rio de Janeiro: Renovar, 2001.

FERNANDES, Luís Carvalho. Teoria geral do direito civil: introdução pressupostos da relação jurídica. 4aㅗ ed. Lisboa: Universidade Católica, 2007.

FESTAS, David de Oliveira. Do conteúdo patrimonial do direito a imagem: contributo para um estudo do seu aproveitamento consentido e inter vivos. Portugal: Coimbra Editora, 2009.

FIGUEIREDO, Fábio Vieira. Direitos da personalidade: o direito de autor e a autonomia privada sobre sua fração extrapatrimonial. In: ALVES, Jones Figueredo, DELGADO, Mário Luiz. (Org.). Questões controvertidas no código civil. São Paulo: Método, 2007. Cap. 9. p. 210-249.

FRADA, Manuel A. Carneiro da. A própria vida como dano?: dimensões civis e constitucionais de uma questão-limite. In: Estudos em honra ao Professor Doutor José de Oliveira Ascensão. Coimbra: Revista da Ordem dos Advogados, 68, I, Jan. 2008

FRANÇA, Rubens Limongi. Do nome civil das pessoas naturais. São Paulo: Revista dos Tribunais, 1958.

. Enciclopédia Saraiva do direito. São Paulo: Saraiva, 1978. v. 28. . Manual de Direito Civil, 4ª . ed. São Paulo: Revista dos Tribunais, 1980. vol. I.

GAGLIANO, Pablo Stolze; PAMPLONA, Rodolfo Filho. Novo curso de direito civil: parte geral. $8^{\underline{a}}$ ed. São Paulo: Saraiva, 2006.

GAMA, Guilherme Calmon Nogueira da. Direito Civil: parte geral. São Paulo: Atlas, 2006 
GAMA, Guilherme Calmon Nogueira; PEREIRA, Daneil Queiroz; PIMENTEL, Juliana Pinto. Novo código civil: situações subjetivas existenciais e situações subjetivas patrimoniais à luz da nova ordem civil. Revista de Direito Privado 23. São Paulo: Revista dos Tribunais, 2005.

GANDELMAN, Henrique. De Gutenberg à Internet. $4^{\underline{a}}$ ed. Rio de Janeiro: Record, 2001.

GEDIEL, José Antonio Peres. Os Transplantes de Órgãos e a Invenção Moderna do Corpo. Curitiba: Moinho do verbo, 2000.

GOGLIANO, Daisy. Direitos privados da personalidade. Dissertação (Mestrado). Faculdade de Direito da Universidade de São Paulo, São Paulo, 1982.

Revista de Direito Sanitário, vol. 1, n. 1, Nov/2000.

GOMES, José Jairo. Direito civil: introdução e parte geral. Belo Horizonte: Del Rey, 2006. vol. I.

GOMES, Júlio Manuel Vieira. O conceito de enriquecimento, o enriquecimento forçado e os vários paradigmas do enriquecimento sem causa. Porto: Coimbra Editora, 1998.

GOMES, Orlando. Novos temas de direito civil. Rio de Janeiro: Forense, 1983.

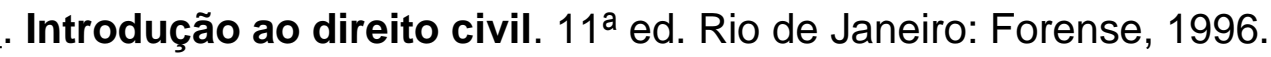
. Direitos da personalidade. Revista Forense Comemorativa 100 anos. Rio de Janeiro: Forense, 2007. . Introdução ao direito civil. 20ํㅡㄹ ed. Rio de Janeiro: Forense, 2010.

GONÇALVES, Diogo Costa. Pessoa e direitos de personalidade: fundamentação ontológica da tutela. Coimbra: Almedina, 2008.

GONÇALVES, Luiz da Cunha. Tratado de direito civil. $2^{2}$. ed. São Paulo: Max Limonad, 1995. 
GURGEL, Fernanda Pessanha do Amaral. Liberdade e direito privado. In: NERY, R.M.A. (Org.) Função do Direito Privado no atual momento histórico. São Paulo: Revista dos Tribunais, 2006.

HÖRSTER, Heinrich Ewald. A parte Geral do Código Civil Português - Teoria Geral do Direito Civil. Coimbra: Almedina, 1992

IUDICA, Giovanni; ZATTI, Paolo. Linguaggio e regole del diritto privato: nuovo manuale per i corsi universitari. Itália: CEDAM, 2005.

KAYSER, Pierre. Les droits de la personnalité: aspects théoriques et pratiques:. RTD civ. n. 11. 1971.

LARENZ, Karl. Metodologia da ciência do direito. Lisboa: Fundação Calouste Gulbenkian, 1983.

LINDON, Raymond. Dictionnaire juridique des droits de la personnalité. Paris: Dalloz, 1983.

LOISEAU, Grégoire. Des droits patrimoniaux de la personnalité en droit français. Montreal: Université McGill, 1997.

LOPES, Cláudia Possi. Limitações aos direitos de autor e de imagem. Revista da Associação Brasileira da Propriedade Intelectual, São Paulo, n.ํ35, 1998.

LOPES, Miguel Maria Serpa. Curso de direito civil: introdução, parte geral e teoria geral dos negócios jurídicos. $7^{\text {a }}$ ed. Rio de Janeiro: Livraria Freitas Bastos S/A, 2000. vol. 1.

LOTUFO, Renan. Código civil comentado: parte geral (arts. $1^{\circ}$ a 232). São Paulo: Saraiva, 2003. v. 1. 
MARINO, L. Traité de droit de la presse et des médias. LexisNexis-Litec, n. 1774, 2009.

MARINONI, Luiz Guilherme. Tutela inibitória (individual e coletiva). 3ª ed. São Paulo: Revista dos Tribunais, 2003.

MARTINS-COSTA, J. Pessoa, personalidade, dignidade: ensaio de uma qualificação. Tese de livre-docência. São Paulo, Faculdade de Direito da Universidade de São Paulo, maio de 2003.

MAZEUAD, Henri., Léon. et Jean. Leçons de droit civil. Introduction à l'étude du droit. 12 ème éd. Paris: L.G.D.J., 2000.

MONCADA, Luís Solano Cabral de. Lições de direito civil. 4aa ed. Coimbra: Almedina, 1995. v.1.

MORAES, Maria Celina Bodin de. Danos à pessoa humana uma leitura civil: constitucional dos danos morais. Rio de Janeiro: Renovar, 2003.

MORATO, Antônio Carlos. Direito de autor em obra coletiva. São Paulo: Saraiva, 2007.

A pessoa jurídica consumidora. São Paulo: Revista dos Tribunais, 2008.

Revista da Faculdalde de Direito da Universidade de São Paulo, v. 106/107, p. $121-158,2011 / 2012$.

NEVES, Celso. Estrutura fundamental do processo civil: tutela jurídica processual, ação, processo e procedimento. Rio de Janeiro: Forense, 1995.

OLLARD, Romain. Qualification de droits extrapatrimoniaux. In.: SAINT-PAUL, J. C,. Droits de la personnalité. Paris: LexisNexis, 2013. 
OTERO, Paulo. Disponibilidade do próprio corpo e dignidade da pessoa humana. In: Estudos em Honra do Professor Doutor José de Oliveira Ascensão. Lisboa: Almedina, 2008. v.1.

PASSARELLI, Francesco Santoro. Dottrine generali del diritto civile. Napoli: Jovene, 1989.

PEREIRA, Caio Mário da Silva. Instituições de direito civil: introdução ao direito civil. $21^{a}$ ed. v. 1. Rio de Janeiro: Forense, 2005.

PERLINGIERI, Pietro. La personalità umana nell'ordinamento giuridico. Nápoli: Jovene, 1972.

PERLINGIERI, Pietro. Perfis do direito civil: introdução ao direito civil constitucional. Trad. de Maria Cristina De Cicco. Rio de Janeiro: Renovar, 1997.

PERREAU, E.H. Des droits de la personnalité : RTD civ. 1909, p. 501. V. Collet, La notion de droit extrapatrimonial, thèse Paris II, 1992.

PINO, Giorgio. Teorie e dottrine dei diritti della personalitá: uno Studio di metagiurisprudenza analítica. In.: Materiali per una storia della cultura giuridica, 2003/1, p. 237-274. Disponível

em: $<$ http://www.estig.ipbeja.pt/ ac_direito/Pino20.pdfhttp://www.estig.ipbeja.pt/ ac_di reito/Pino20.pdf $\geq$. Acesso: 20 nov. 2011.

PINTO, Carlos Alberto da Mota. Teoria geral do direito civil. $4^{\mathrm{a}}$ ed. Coimbra: Coimbra Editora, 2005.

PINTO, Paulo da Mota. O direito ao livre desenvolvimento da personalidade. Boletim da Faculdade de Direito da Universidade de Coimbra. Portugal-Brasil, Ano 2000, Coimbra Editora, 1999.

A limitação voluntária do direito à reserva sobre a intimidade da vida privada. Revista Brasileira de Direito Comparado. Rio de Janeiro: Instituto de Direito Comparado Luso-brasileiro, n. 21, p. 21-62, jul./dez., 2001. 
. Direitos da personalidade no código civil português e no novo código civil brasileiro. Revista Jurídica. v. 51, n. 314.

Notas sobre o direito ao livre desenvolvimento da personalidade e os direitos de personalidade no direito português, in $\mathrm{A}$ constituição concretizada - construindo pontes com o público e o privado. Porto Alegre: Livraria do Advogado, 2000

PONTES DE MIRANDA, Francisco Cavalcanti. Tratado de direito privado. Campinas: Brookseller, 2000. v.2.

PUECHE, Enrique Bustos. Manual sobre bienes y derechos de la personalidade. Madrid: Dikynson, 1997.

RESTA, Giorgio. Diritti della personalitá: problemi e prospettive. Millano: Giuffre, 2007.

RIBEIRO, Joaquim de Sousa. Constitucionalização do direito civil. In:

Direito dos Contratos: estudos. Coimbra: Coimbra Editora, 2007.

RUGGIERO, Roberto de. Instituições de direito civil, introdução e parte geral: direito das pessoas. $2^{\underline{a}}$ ed. Campinas: Bookseller, 2005. v.1.

SAVIGNY, Friedrich Carl von. Sistema do direito romano atual. Ijuí: Editora da Unijui, 2004. v.1.

SOUSA, Rabindranath Valentino Aleixo Capelo de. O Direito Geral de Personalidade. Coimbra: Coimbra Editora, 1995.

STOCCO, Rui. Responsabilidade civil e sua interpretação jurisprudencial. $4^{a}$ ed. São Paulo: Revista dos Tribunais, 1999.

SZANIAWSKI, Elimar. Direitos da personalidade e sua tutela. São Paulo: Revista dos Tribunais, 1993. 
TEPEDINO, Gustavo. A parte geral do novo código civil: estudos na perspectiva civil-constitucional. 2ª ed. Rio de Janeiro: Renovar, 2003.

. Temas de Direito Civil, 4⿳亠丷a. ed. Rio de Janeiro: Renovar, 2008.

THIENE, Arianna. L'immagine fra tutela risarcitoria e restitutoria. In: La nuova giurisprudenza civile commentata. N.7-8 Luglio-Agosto 2011. Ano XXVII, Revista Mensile. CEDAM.

TOBEÑAS, José Castan. Los derechos de la personalidad. Madri: Instituto Editorial Reus, 1952.

TORRES, Patrícia de Almeida. Direito à própria imagem. São Paulo: LTR, 1998.

URCIUOLI, Maria Antonietta. Autonomia negoziale e diritto all'immagine. Napoli: Edizioni Scientifiche Italiane, 2000.

VARELA, João de Matos Antunes; LIMA, Fernando Andrade Pires de. Noções Fundamentais de Direito Civil. Coimbra: Coimbra Editora, 1950.

VASCONCELOS, Pedro Pais. Direitos da personalidade. Almedina: Coimbra, 2006.

VERCELLONE, Paolo. II diritto sul proprio ritratto. Torino: UTET, 1959.

. Diritti della personalità e <right of publicity>. In Riv. trim. dir. e proc. civ., 1995.

ZANINI, Leonardo Estevam de Assis. Direitos da personalidade: aspectos essenciais. São Paulo: Saraiva, 2011.

ZENAT- CASTAING, Frédéric; THIERRY, Revet. Manuel de droit des personnes. Paris: Presses Universitaires de France - PUF, 2006. n. 257. 
ZENO-ZENOVICH, Vincenzo. Diritti della personalità. In: A. Belvedere-R. Guastini-P. Zatti-V. Zeno-Zenovich. Glossario in Trattato di diritto privato. Milano: G. lurica P. Zatti, 1998. 